\title{
Nitrofurantoin Cytotoxicity
}

\author{
IN VITRO ASSESSMENT OF RISK BASED \\ ON GLUTATHIONE METABOLISM
}

\author{
STEPHEN P. SPIElBERG and GARY B. GoRdON with the technical assistance of \\ LyNETTE LOMBARDI, Departments of Pediatrics and Pharmacology and \\ Experimental Therapeutics, Division of Clinical Pharmacology, Johns Hopkins \\ University School of Medicine, Baltimore, Maryland 21205
}

A B S T R A C T Nitrofurantoin, a commonly used urinary tract antiseptic, has been associated with idiosyncratic pulmonary and hepatic damage. We have used human lymphocytes in vitro to explore the biochemical basis of susceptibility to nitrofurantoin toxicity. The drug itself did not damage the cells as assessed by trypan blue dye exclusion. In the presence of a mouse hepatic microsomal drug-activating system, however, nitrofurantoin metabolites produced dose-dependent toxicity to the lymphocytes. Inhibition of the enzyme epoxide hydrolase did not enhance toxicity; the metabolite thus does not appear to be a furan epoxide. Binding of reactive metabolites to cell macromolecules may lead directly to cell death, or in vivo, by acting as haptens to secondary immunologic responses. The metabolite caused a dosedependent depletion of lymphocyte glutathione content. Cells from a patient with glutathione synthetase deficiency showed markedly enhanced nitrofurantoin toxicity. The findings suggest that glutathione plays a major role in protecting cells from nitrofurantoin-induced damage, and that studies of lymphocyte toxicity and glutathione metabolism in patients experiencing idiosyncratic reactions to nitrofurantoin may lead to elucidation of the biochemical and genetic basis of drug susceptibility.

\section{INTRODUCTION}

Nitrofurantoin is one of the most commonly used urinary tract antiseptics. When used as a prophylactic agent, patients are exposed to the drug over prolonged

Dr. Spielberg is a recipient of a Faculty Development Award from the Pharmaceutical Manufacturers Association Foundation.

Received for publication 29 May 1980 and in revised form 25 August 1980. periods. Although the incidence of side effects is relatively low, hemolytic anemia, peripheral neuropathy, pulmonary edema and fibrosis, and hepatic damage may occur (1). Recently, there have been increasing reports of chronic active hepatitis including deaths from progressive hepatic failure attributed to the compound $(2,3)$. The mechanisms of nitrofurantoin toxicity are incompletely understood. There is evidence for formation of a reactive, electrophilic metabolite that can covalently bind to cell macromolecules (4). Such metabolites of a variety of drugs have been implicated as mutagens, carcinogens, teratogens, hepatotoxins, and, by acting as haptens, may lead to secondary immune responses including drug-induced lupus (5-8).

We have been studying the role of reactive metabolites in human idiosyncratic drug reactions, particularly hepatotoxicity, using an in vitro assay containing human lymphocytes and a mouse liver drug metabolizing system (9). Lymphocyte toxicity from metabolites produced by the microsomes is assessed, and cellular defenses against toxicity can be explored. Many electrophilic metabolites are conjugated with glutathione. Thus, acetaminophen, in the presence of microsomes in the system, can cause dose-dependent depletion of lymphocyte glutathione content with attendant cytotoxicity, similar to the hepatotoxicity caused by overdoses of the drug in vivo $(9,5)$. Lymphocytes from patients with inherited deficits in glutathione synthesis show increased acetaminophen toxicity (10). The system then may be able to differentiate individual differences in susceptibility to toxicity based on glutathione metabolism. Similarly, epoxide hydrolase serves as a major cell defense against epoxide metabolites $(11,12)$. The in vitro system was used to demonstrate the role of arene oxide metabolites in anticonvulsant cytotoxicity by 
observing increased toxicity in the presence of epoxide hydrolase inhibitors. ${ }^{1}$

We now have applied the in vitro lymphocyte approach to examine if nitrofurantoin or its metabolites is cytotoxic, to explore the nature of the metabolites, and to gain insight into the cellular mechanisms involved in preventing toxicity.

\section{METHODS}

Patients. Lymphocytes from a patient with glutathione synthetase deficiency with 5-oxoprolinuria were compared with cells from several normal controls. The patient has been described in detail elsewhere $(13,14)$. His cells, including erythrocytes, leukocytes, and fibroblasts, have $10-20 \%$ normal enzyme activity and intracellular glutathione content.

Preparation of lymphocytes. Human lymphocytes were aseptically isolated from fresh, heparinized blood. Blood was diluted threefold with Eagle's minimal essential medium (Gibco Laboratories, Grand Island Biological Co., Grand Island, N. Y.) and layered on Ficoll-Paque (Pharmacia Fine Chemicals, Div. Pharmacia Inc., Piscataway, N. J.). Gradients were spun at $500 \mathrm{~g}$ for $30 \mathrm{~min}$. Lymphocytes were removed from the aqueous-Ficoll interface and diluted with a Hepes-buffered salt medium containing 15 $\mathrm{mM}$ Hepes, pH 7.4, $125 \mathrm{mM} \mathrm{NaCl}, 6 \mathrm{mM} \mathrm{KCl}, 1.2 \mathrm{mM}$ $\mathrm{MgSO}_{4}, 1 \mathrm{mM} \mathrm{NaH}_{2} \mathrm{PO}_{4}, 1 \mathrm{mM} \mathrm{CaCl}_{2}$, and $10 \mathrm{mM}$ glucose. Cells were collected at $1,000 \mathrm{~g}$, washed once in the Hepes medium, and resuspended in Hepes to yield $10^{6}$ cells per $750 \mu \mathrm{l}$.

Preparation of microsomes. 6-wk old, male National Institutes of Health General Purpose Swiss Mice (N:GP[SW]) were pretreated with $60 \mathrm{mg} / \mathrm{kg}$ of phenobarbital intraperitoneally daily for $3 \mathrm{~d}$. Animals were killed by cervical dislocation, and livers aseptically removed. All subsequent procedures were carried out with sterile precautions at $4^{\circ} \mathrm{C}$. Tissue was homogenized in $3 \mathrm{vol}$ ( wt/vol) of $0.15 \mathrm{M} \mathrm{KCl}$ in a Polytron (Kinematica, Luzern, Switzerland) homogenizer. The homogenate was spun at $500 \mathrm{~g}$ for $10 \mathrm{~min}$. The supernate was then spun at $9,000 \mathrm{~g}$ for $15 \mathrm{~min}$, and the resulting supernate at $100,000 \mathrm{~g}$ for $1 \mathrm{~h}$. The pellet was resuspended in $0.15 \mathrm{M} \mathrm{KCl}$ and spun at $100,000 \mathrm{~g}$ to decrease the glutathione content of the microsomes. The pellet was suspended and homogenized in $0.15 \mathrm{M} \mathrm{KCl}$ to yield $0.5 \mathrm{mg}$ of protein per $50 \mu \mathrm{l}$. (Microsomes contained $\sim 0.1 \mu \mathrm{g}$ glutathione/mg protein). Aliquots were frozen and stored at $-80^{\circ} \mathrm{C}$.

Incubation conditions. $10^{6}$ cells in Hepes-buffered medium and $0.5 \mathrm{mg}$ of microsomal protein were incubated with $0.6 \mathrm{mM} \mathrm{NADP}^{+}, 2.4 \mathrm{mM}$ glucose-6-phosphate, $2 \mathrm{U}$ glucose6-phosphate dehydrogenase (Type XV) and varying concentrations of nitrofurantoin in a final volume of $1 \mathrm{ml}$. (All chemicals were obtained from Sigma Chemical Co., St. Louis, Mo.) Incubations were carried out at $37^{\circ} \mathrm{C}$ for $2 \mathrm{~h}$. An aliquot of cells was taken for determination of total glutathione content (15) and protein (16). Cells were spun, washed with normal saline, spun, and finally sonicated in $0.02 \mathrm{~N} \mathrm{HCl}$ for the assays. The remainder of the sample was used for toxicity assays.

Assessment of toxicity. Following the 2-h drug challenge and removal of aliquots, cells were spun and resuspended in

\footnotetext{
${ }^{1}$ Spielberg, S. P., G. B. Gordon, D. A. Blake, D. Bross, and D. Mellits. Anticonvulsant toxicity in vitro: role of arene oxide metabolites. Submitted for publication.
}

TABLE I

Effect of Nitrofurantoin on Lymphocyte Toxicity in the Presence of the Microsomal System, and with or without Trichloropropene Oxide

\begin{tabular}{ccc}
\hline & \multicolumn{2}{c}{ TCPO $^{*}$} \\
\cline { 2 - 3 } Nitrofuratoin & \multicolumn{3}{c}{5} \\
\hline$\mu M$ & & $\mu g / m l$ \\
0 & $12.9 \pm 2.1 \ddagger$ & $13.9 \pm 1.5$ \\
6.25 & $21.2 \pm 3.1$ & $18.1 \pm 2.2$ \\
12.50 & $26.7 \pm 2.2$ & $25.1 \pm 1.6$ \\
25.00 & $34.7 \pm 3.2$ & $34.1 \pm 0.8$ \\
50.00 & $39.3 \pm 1.5$ & $35.6 \pm 3.0$ \\
100.00 & $39.8 \pm 3.3$ & $43.8 \pm 2.7$ \\
\hline
\end{tabular}

* TCPO, an inhibitor of epoxide hydrolase, was added to cells $10 \mathrm{~min}$ before adding microsomes and nitrofurantoin.

$\$$ Values represent percent dead cells by trypan blue dye exclusion, mean \pm SEM for four determinations. Analyzed by analysis of variance, nitrofurantoin caused a dosedependent increase in cell death for samples with and without TCPO $(P<0.01)$, but TCPO did not alter the toxicity of nitrofurantoin $(P>0.5)$.

Hepes-buffered medium containing $5 \mathrm{mg} / \mathrm{ml}$ of albumin (Fraction V, Sigma Chemical Co.) Incubation was continued at $37^{\circ} \mathrm{C}$ for $16 \mathrm{~h}$. An aliquot was taken for trypan blue dye exclusion; failure to exclude dye was used as an index of cell death.

Studies on epoxide hydrolase. To assess the role of epoxide hydrolase as a cell defense in nitrofurantoin toxicity, cell aliquots were pretreated for $10 \mathrm{~min}$ with 1,1,1-trichloro-2-propene oxide (TCPO, ${ }^{2}$ Aldrich Chemical Co., Milwaukee, Wisc.; $5 \mu \mathrm{g} / \mathrm{ml}$ final concentration), a potent inhibitor of the enzyme (11). The microsomal system and nitrofurantoin were then added, and incubations and toxicity studies performed as above. The dosage of TCPO chosen was the maximum associated with no cell toxicity in the absence of nitrofurantoin. We have previously shown that TCPO at this concentration can enhance the toxicity of arene oxide metabolites of aromatic anticonvulsants in the system. ${ }^{1}$

\section{RESULTS}

Nitrofurantoin toxicity in the presence of the microsomal system. When the full microsomal system was included in the incubation mixture, nitrofurantoin caused a dose-dependent increase in cell death (Table I). Preincubation of cells with an epoxide hydrolase inhibitor, TCPO, did not enhance toxicity. Omission of the microsomes, NADPH-generating system, or both, abolished the nitrofurantoin-induced toxicity.

Nitrofurantoin produced a dose-dependent depletion of lymphocyte glutathione content (Table II).

\footnotetext{
${ }^{2}$ Abbreviation used in this paper: TCPO, 1,1,1-trichloro2-propene oxide.
} 
TABLE II

Effect of Nitrofurantoin and Acetaminophen on

Lymphocyte Glutathione Content and Toxicity in the Presence of the Microsomal System

\begin{tabular}{ccr}
\hline Drug & Total glutathione & $\begin{array}{c}\text { Percent dead } \\
\text { cells }\end{array}$ \\
\hline$\mu M$ & $\mu g / m g$ protein & \\
0 & $2.64 \pm 0.24^{*}$ & $10.0 \pm 0.9 \ddagger$ \\
Nitrofurantoin & & \\
0.01 & $2.34 \pm 0.07$ & $16.3 \pm 1.9$ \\
0.10 & $2.22 \pm 0.27$ & $42.1 \pm 1.3$ \\
1.00 & $1.58 \pm 0.18$ & $48.1 \pm 1.1$ \\
Acetaminophen & & \\
0.1 & $1.30 \pm 0.20$ & $9.9 \pm 1.0$ \\
1.0 & $0.69 \pm 0.07$ & $18.5 \pm 1.4$ \\
10.0 & $0.14 \pm 0.02$ & $29.5 \pm 1.2$ \\
\hline
\end{tabular}

* Values represent mean \pm SEM for four determinations. Total glutathione was assayed by the method of Tietze (15) and protein according to Lowry et al. (16).

\$ Values represent percent dead cells, mean \pm SEM for four determinations. Dose-dependent effects of nitrofurantoin on glutathione content and cell death were both significant $(P<0.05)$ by analysis of variance. The effects of acetaminophen on both parameters differed significantly from those of nitrofurantoin $(P<0.01)$.

The decrease in glutathione was not due to oxidation of reduced to oxidized tripeptide, but a decrease in total glutathione content. Toxicity to cells was evident at concentrations leading to only a small $(10-15 \%)$ depletion of glutathione. Data on acetaminophen-induced glutathione depletion and toxicity are shown for comparison with the nitrofurantoin findings. Acetaminophen metabolites led to more glutathione depletion, but produced cell toxicity only after glutathione had been depleted by $>70 \%$.

Nitrofurantoin toxicity in glutathione synthetasedeficient lymphocytes. The glutathione content of lymphocytes from the patient with glutathione synthetase deficiency was $0.59 \pm 0.02 \mu \mathrm{g} / \mathrm{ml}$ protein compared with $2.60 \pm 0.16 \mu \mathrm{g} / \mathrm{ml}$ protein for four normal controls. Toxicity is shown in Fig. 1. The glutathione synthetase deficient cells showed a marked increase in susceptibility to nitrofurantoin damage. Base-line toxicity in the presence of microsomes without nitrofurantoin did not differ between normal and mutant cells.

\section{DISCUSSION}

Exploration of the pathogenesis of idiosyncratic drug reactions is limited by the paucity of noninvasive approaches for assessing individual differences in susceptibility to drug toxicity. In the case of nitrofurantoin, there is increasing recognition of the

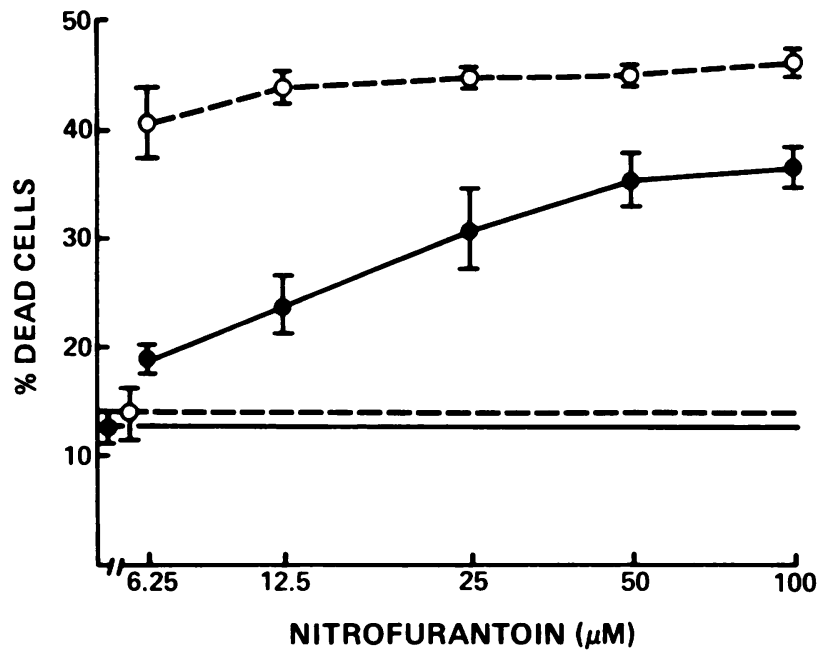

FIGURE 1 Nitrofurantoin toxicity in the presence of the microsomal system in glutathione synthetase deficient $(\mathrm{O}--\mathrm{O})$ and normal (O_- lymphocytes. Base line percent dead cells in the absence of drug is shown by horizontal lines ([- - ] for deficient, [-] for normal cells) with 1 SEM indicated at the left of the graph. Base-line toxicity did not differ between normal and deficient cells. Points shown represent mean \pm SEM for three determinations on glutathione synthetase-deficient cells, and two determinations each on cells from four normal individuals. The effect of nitrofurantoin on glutathione synthetase deficient cells differed significantly from normal controls $(P<0.01)$ by analysis of variance.

potential for pulmonary and hepatic injury in some patients, and recent studies of the role of drug metabolism in toxicity at a biochemical level. It has not yet been possible, however, to apply the available biochemical understanding to evaluate why some individuals exhibit increased sensitivity to nitrofurantoin-induced injury.

Case reports of chronic active hepatitis with prolonged use of nitrofurantoin have included biochemical and liver biopsy evidence for direct hepatocellular toxicity, as well as immunologic reactions including hyperglobulinemia, and antinuclear and antismooth muscle antibodies in some patients $(2,3)$. The role of the immune phenomena in the pathogenesis of the hepatic damage is unclear; antinuclear antibodies have persisted in some patients long after discontinuation of the drug and improvement in hepatic function. Some patients also have had evidence of pulmonary damage. Cellular injury could result from metabolism of the drug to a reactive, electrophilic intermediate capable of covalently binding to cell macromolecules (4). While furan-containing compounds may be metabolized to cytotoxic epoxides (17), it has been suggested that nitrofurantoin may undergo nitroreduction of the nitrate group on the furan ring, similar to some other 
nitrofurans $(4,18)$. The structure of nitrofurantoin is shown in Fig. 2. Nitrofurantoin also could cause tissue damage by formation of superoxide from redox cycling of the drug by microsomes in the presence of oxygen, similar to the postulated mechanism of toxicity of paraquat (19).

In the present studies, we have used human lymphocytes as target cells to examine the biochemical basis for variation in response to nitrofurantoin toxicity. When cells were incubated with the drug in the absence of microsomes, no toxicity occurred. The parent drug does not appear to be toxic, and lymphocytes in this system do not produce significant amounts of toxic metabolites, similar to results obtained with acetaminophen (9). When microsomes were included in the reaction, nitrofurantoin produced a dose-dependent increase in cell death. Toxicity was not enhanced by TCPO. The toxic metabolite thus does not appear to be a furan epoxide, consistent with the postulated importance of the nitroreduction pathway (4). The metabolite generated in our system is directly cytotoxic. In vivo, such a metabolite produced in the liver could lead to hepatocellular damage. Secondary immune phenomena then could result from covalently bound metabolite acting as a hapten, or release of altered proteins from dead or damaged cells.

Nitrofurantoin metabolites produced a dose-dependent depletion of lymphocyte total glutathione content, presumably due to conjugation of drug metabolites with glutathione. The dose response for glutathione depletion and cytotoxicity was different from that obtained with acetaminophen (Table II). Metabolites of the latter must first deplete glutathione content substantially before covalent binding and toxicity occur. Availability of metabolites to interact with cell macromolecules and produce toxicity may depend on the relative rates of formation from the parent compound and affinities for interaction with glutathione, enzymes involved in detoxification, and other cellular nucleophilic sites.

The role of glutathione in protecting cells from nitrofurantoin injury was confirmed by studying cells from a patient with glutathione synthetase deficiency. The cells, with $\sim 20 \%$ of normal glutathione content, exhibited marked increased susceptibility to nitro-

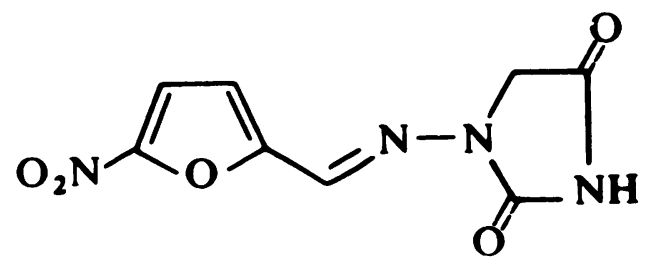

FIGURE 2 The structure of nitrofurantoin. furantoin. This was particularly striking at lower concentrations, in the range of plasma levels achieved in clinical use. The results suggest that such patients may be at high risk for toxicity from the drug. Although patients with glutathione synthetase deficiency are rare, there is a considerable range of cell glutathione content in the normal population (20). Variation of glutathione-mediated detoxification thus could play a role in idiosyncratic toxicity to nitrofurantoin.

Ultimate outcome on exposure to a drug such as nitrofurantoin will probably depend on many genetic loci controlling metabolic activation, glutathione synthesis, degradation, and conjugation, as well as environmental variables. Our results, however, suggest that examination of toxicity and glutathione metabolism using an in vitro lymphocyte system may well lead to elucidation of the biochemical and genetic basis of altered susceptibility in some patients experiencing adverse reactions to nitrofurantoin.

\section{ACKNOWLEDGMENTS}

We would like to thank Phyllis Schoppert for typing the manuscript, and Dr. David A. Blake for helpful discussions. This work was supported by a Basil O'Connor Research Starter Grant from the March of Dimes Birth Defects Foundation.

\section{REFERENCES}

1. Goodman, L. S., and A. Gilman. 1975. In The Pharmacologic Basis of Therapeutics. 5th edition. MacMillan Inc., New York. 1008-1009.

2. Sharp, J. R., K. G. Ishak, and H. J. Zimmerman. 1980. Chronic active hepatitis and severe hepatic necrosis associated with nitrofurantoin. Ann. Intern. Med. 92: 1419.

3. Black, M., L. Rabin, and N. Schatz. 1980. Nitrofurantoininduced chronic active hepatitis. Ann. Intern. Med. 92: 62-64.

4. Boyd, M. R., A. W. Stiko, and H. A. Sasame. 1979. Metabolic activation of nitrofurantoin-possible implications for carcinogenesis. Biochem. Pharmacol. 28: 601-606.

5. Mitchell, J. R., and D. J. Jollow. 1975. Metabolic activation of drugs to toxic substances. Gastroenterology. 68: $392-410$.

6. Nebert, D. W., and N. M. Jensen. 1979. The Ah locus: genetic regulation of the metabolism of carcinogens, drugs, and other environmental chemicals by cytochrome P-450 mediated monooxygenases. CRC Crit. Rev. Biochem. 6: 401-437.

7. Martz, F., C. Failinger, and D. A. Blake. 1977. Phenytoin teratogenesis: correlation between embryopathic effect and covalent binding of putative arene oxide metabolite in gestational tissue. J. Pharmacol. Exp. Ther. 203: 231-239.

9. Spielberg, S. P. 1980. Acetaminophen toxicity in human lymphocytes in vitro. J. Pharmacol. Exp. Ther. 213: 395-398.

10. Spielberg, S. P. and G. B. Gordon. 1980. Increased acetaminophen toxicity in glutathione synthetase deficient lymphocytes. Pediatr. Res. 14: 473. (Abstr.) 
11. Oesch, F., N. Kaubisch, D. M. Jerina, and J. W. Daly. 1971. Hepatic epoxide hydratase. Structure activity relationships for substrates and inhibitors. Biochemistry. 10: 4858-4866.

12. Oesch, F. 1979. Epoxide hydratase. In Progress in Drug Metabolism. J. W. Bridges and L. F. Chasseaud, editors. John Wiley \& Sons, Ltd. Chichester. 3: 253-301.

13. Spielberg, S. P., L. I. Kramer, S. I. Goodman, J. Butler, F. Tietze, P. Quinn, and J. D. Schulman. 1977. 5-Oxoprolinuria: biochemical observations and case report. $J$. Pediatr. 91: 237-241.

14. Spielberg, S. P., M. D. Garrick, J. Butler, F. Tietze, L. Corash, and J. D. Schulman. 1978. Biochemical heterogenity in glutathione synthetase deficiency.J. Clin. Invest. 61: 1417-1420.

15. Tietze, F. 1969. Enzymic method for quantitative determination of nanogram amounts of total and oxidized glutathione. Anal. Biochem. 27: 502-522.
16. Lowry, O. H., N. J. Rosenbrough, A. L. Farr, and R. J. Randall. 1951. Protein determinations with the Folin phenol reagent. J. Biol. Chem. 193: 265-275.

17. Boyd, M. R. 1977. Evidence for the Clara cell as a site of cytochrome P-450-dependent mixed function oxidase activity in the lung. Nature (Lond.) 269: 713-715.

18. Wang, C. Y., C. W. Chiu, and G. T. Bryan. 1975. Metabolism and disposition of $\mathrm{N}$-(4-(5-nitro-2-furyl)- $\left(2-{ }^{14} \mathrm{C}\right)$ thiazolyl) acetamide in the rat. Drug Metab. Dispos. 3: 89-95.

19. Sasame, H. A., and M. R. Boyd. 1979. Superoxide and hydrogen peroxide production and NADPH oxidation stimulated by nitrofurantoin in lung microsomes: possible implications for toxicity. Life Sci. 24: 1091- 1096.

20. Butler, J. DeB., S. P. Spielberg, F. Tietze, and J. D Schulman. 1979. Variability of enzymes of the $\gamma$-glutamyl cycle in skin fibroblasts during growth. Fed. Proc. 36: 2010. (Abstr.) 